\title{
Elementos para a Crítica da Lei Rouanet e para uma Análise das Produções Artístico-culturais no Brasil ${ }^{1}$
}

\author{
Elementos para la Crítica a la Ley Rouanet y para un Análisis de las \\ Producciones Artístico-culturales en Brasil \\ Elements for a Critique of the Rouanet Law and for an Analysis of Artistic- \\ cultural production in Brazil
}

\author{
Júlia Conterno Rodrigues ${ }^{2}$
}

\begin{abstract}
Resumo
Neste artigo, busca-se apresentar a Lei Rouanet como principal política cultural do Estado brasileiro atual e analisar as consequências de sua forma de operação nas propostas artístico-culturais. Considera-se que um determinado tipo de política cultural direciona e permite, como tendência, um tipo específico de criação. Assim, a Lei Rouanet, que possibilita o patrocínio de propostas artístico-culturais por meio da renúncia fiscal de empresas públicas e privadas, está imersa em uma trama de relações de poder entre os produtores culturais, o Estado brasileiro e as empresas financiadoras. Busca-se aqui evidenciar algumas consequências negativas desta forma de financiamento, tratando a cultura como imbricada no âmbito político da vida social - proposta central dos Estudos Culturais britânicos e suas derivações -, desde uma perspectiva interdisciplinar que se apoia principalmente na sociologia da arte e da cultura e na teoria crítica latino-americana. Toca-se em temas como o Estado latino-americano - a partir do caso brasileiro -, a subordinação dos projetos a dinâmicas mercantis e as práticas artístico-culturais como ações comunicativas que imprimem sentido à nossa realidade. Contudo, a principal contribuição deste trabalho está nas reflexões centradas nos elementos das propostas que devem ser adequados às demandas das empresas financiadoras e os possíveis desenlaces de tal processo. Desta forma, espera-se poder colaborar com futuras pesquisas direcionadas à construção de uma crítica mais profunda e estrutural sobre as relações entre políticas públicas para a cultura, o Estado brasileiro e as produções culturais.
\end{abstract}

Palavras-chave: Lei Rouanet; mercantilização da cultura; Ministério da Cultura do Brasil; políticas culturais.

\section{Resumen}

En este artículo, se busca presentar a la Ley Rouanet como principal política cultural del Estado brasileño actual y analizar las consecuencias de su forma de operación en las propuestas artístico-culturales. Se considera que un determinado tipo de política cultural direcciona y permite, como tendencia, un tipo específico de creación. Así, la Ley Rouanet, que posibilita el patrocinio de propuestas artístico-culturales por medio de la renuncia fiscal de empresas públicas y privadas, está inmersa en un entramado de relaciones de poder entre los productores culturales, el Estado brasileño y las empresas financiadoras. Se busca evidenciar algunas consecuencias negativas de esta forma de financiamiento, tratando a la cultura como imbricada en el ámbito de lo político -planteamiento central de los Estudios Culturales británicos y sus derivaciones-, desde una perspectiva interdisciplinaria que considera principalmente a la sociología del arte y de la cultura y la teoría crítica latinoamericana. Se toca en temas como el Estado latinoamericano - a partir del caso brasileño-, la

\footnotetext{
${ }^{1}$ Este artigo consiste em um recorte do trabalho de investigação que resultou na dissertação de mestrado intitulada "Políticas Culturais no Estado Brasileiro: uma Análise Crítica das Consequências da Lei Rouanet nas Propostas Artístico-Culturais.", escrita originalmente em espanhol, realizada entre os anos de 2014 e 2016 no contexto de um programa de mestrado em Comunicación y Política da Universidad Autónoma Metropolitana (UAM-X), sediada no México.

${ }^{2}$ Mestre em Comunicação e Política pela Universidad Autónoma Metropolitana unidad Xochimilco (UAM-X), Ciudad de México, Distrito Federal, México. E-mail: juconterno@gmail.com Trabalho apresentado no I Seminário Latino-Americano de Estudos em Cultura - SEMLACult, Foz do Iguaçu/PR, Brasil, 2017.
} 
subyugación de los proyectos a dinámicas mercantiles y las prácticas artístico-culturales como acciones comunicativas que imprimen sentido a nuestra realidad. Empero, la principal contribución de este trabajo está en las reflexiones centradas en los elementos de las propuestas que deben adecuarse a las demandas de las empresas financiadoras y los posibles desenlaces de tal proceso. De esta forma, se espera poder colaborar con futuras investigaciones que estén direccionadas a tejer críticas más profundas y estructurales sobre las relaciones entre políticas públicas para la cultura, el Estado brasileño y las producciones culturales.

Palabras claves: Ley Rouanet; mercantilización de la cultura; Ministerio de Cultura de Brasil; políticas culturales.

\begin{abstract}
This article aims to present the Rouanet Law as the main cultural policy of the current Brazilian State and to analyze the consequences occasioned from its dynamics in the artistic-cultural proposals. It considers that a certain type of cultural policy addresses and allows, as a tendency, a specific type of creation. Thus, the Rouanet Law, that regulates the sponsoring of artistic-cultural proposals by public and private enterprises tax waiver, is embedded in a framework of power relations between cultural producers, the Brazilian State and enterprises. It seeks to show some negative consequences of this manner of financing, taking culture as imbricated in the realm of politics - thesis of British Cultural Studies and its derivations - from an interdisciplinary perspective that considers mainly the sociology of art and culture and critical Latin American theory. It touches upon themes such as the Latin American State - from the perspective of the Brazilian case -, the subjugation of projects to mercantile dynamics and the artistic-cultural practices as communicative actions that impart sense to our reality. However, the main contribution of this work is placed in the reflections focused on the elements of the proposals that must be adapted to the demands of the sponsoring enterprises and the possible outcomes of such a process. In this way, it aims to be able to collaborate with future investigations that are directed to hatch deeper and structural critique on the relations between public policies for the culture, the Brazilian State and cultural productions.
\end{abstract}

Keywords: cultural commodification; cultural policies; Culture Ministry of Brazil; Rouanet Law.

\title{
1. Cultura e políticas públicas: a marca da Lei Rouanet
}

A Lei Rouanet tem sido um dos principais núcleos do debate sobre a atuação do Ministério da Cultura do Brasil nos últimos anos: como principal política cultural a nível federal de governo, ela possibilita a execução de aproximadamente $1.300^{3}$ propostas artístico-culturais ao ano através do desembolso de recursos de doadores ou patrocinadores. Seu tempo de vida útil de mais de 25 anos e seu peso com relação aos recursos públicos federais totais para a cultura nos permitem afirmar que o cenário recente da produção cultural no Brasil está marcado pela Lei Rouanet. ${ }^{4}$

Em breves palavras, o mecenato privado, principal instrumento de financiamento a projetos artístico-culturais previsto pela Lei Rouanet, é a modalidade na qual uma grande empresa desembolsa recursos para financiar um projeto e, posteriormente, recebe em troca isenção

\footnotetext{
${ }^{3}$ Informação proporcionada por Alexandra Costa, então Diretora de Inventivo à Cultura, vinculada à Secretaria de Fomento e Inventivo à Cultura (Sefic) do Ministério da Cultura, em entrevista realizada dia 31 de março de 2016. Os dados com relação à quantidade de projetos finalizados ao ano via Lei Rouanet não constam no SalicNet.

${ }^{4}$ Veremos em maiores detalhes este orçamento nas páginas 6-8 deste artigo.
} 
parcial de seus impostos de renda devidos ao governo federal. Para que um projeto artísticocultural seja financiado por esta via, este deve ser aprovado pelo Ministério da Cultura (MinC) e posteriormente oferecido pelo proponente a uma empresa (pública ou privada) ou a uma pessoa física, que decide por financiá-lo ou não. De saída, adiantamos aqui que a maioria dos projetos que concorrem à Lei Rouanet são financiados por grandes empresas privadas, que o fazem em troca de, além do benefício fiscal, um bom retorno publicitário. É nesta modalidade, o mecenato privado, que centramos a busca de dados e as análises neste trabalho. A partir do primeiro governo do Partido dos Trabalhadores (PT), em 2003, com Gilberto Gil à frente do MinC, ampliaram-se as vias para o debate e a participação cidadã; desta forma, o até então moribundo Ministério passa a ser permeado por mais discussões e novas possibilidades de atuação, amparados por um discurso ministerial que passou a assignar à cultura um papel primordial no desenvolvimentos da nação. Por outro lado, apesar da nova cara dada ao Ministério da Cultura, este permaneceu afastado do núcleo fundamental da disputa e da atuação governamental central para o tipo de desenvolvimento que queremos e necessitamos para um país como o Brasil. Ou seja, entre o discurso e a aparência ministeriais e as conquistas concretas em matéria de cultura, ainda persiste um abismo de distância. Ficou claro, então, que não se avança na política pura e simplesmente com participação cidadã em fóruns e canais de comunicação com o governo e que tampouco a presença de políticos progressistas no Ministério são garantias de uma transformação radical do mísero cenário no qual se encontravam as políticas públicas para a cultura no país.

Parecia que enfrentar os obstáculos para criar e consolidar um amplo programa para a cultura no país implicaria um debate mais profundo visando uma transformação radical; porém, diante da penúria de recursos e o persistente alheamento do Ministério da Cultura na agenda nacional - que de fato impossibilitaram a concreção de algumas mudanças imaginadas pelo Ministério -, grande parte da classe artística acabou por limitar a disputa dentro dos marcos da Lei Rouanet, dando mais ênfase a discussões sobre sua distribuição e volume de financiamento, sob a premissa de que "mal com ela, mas pior sem ela".

Dito isso, a problematização que buscamos plasmar nestas páginas está inscrita no domínio da cultura e do político. Cultura, este conceito complexo e polissêmico que arrasta toda uma genealogia de pensamento acadêmico que passa principalmente pela filosofia, linguística, sociologia e antropologia para chegar hoje, como escreve Stuart Hall (2014b: 53, tradução nossa), "a seu atual estado de (in)determinação". Não propomos aqui reconstruir este debate em detalhes e tampouco buscamos oferecer uma definição lógica e precisa do conceito de cultura. Nos limitamos simplesmente a afirmar que tomamos sua definição da antropologia e 
da sociologia: como uma dimensão da vida humana - indispensável para a afirmação desta como tal (Echeverría, 2010: 17-25, tradução nossa) - que inter-relaciona as práticas e discursos sociais com processos simbólicos; um vívido sistema de valores que rege as ações humanas, elabora a significação das estruturas sociais, formado de saberes, hábitos, regras, conhecimento etc. Uma dimensão das atividades humanas que, apesar de pertencer ao âmbito do simbólico, está também vinculada às condições materiais de existência de um grupo de indivíduos em um momento histórico dado. Desta forma, como qualquer atividade ou processo humano, está situado social e politicamente, livrando-se da prerrogativa de autonomia e neutralidade que ainda persiste em algumas concepções do termo. Por outro lado, assumimos o político como constitutivo da cultura - e trata-se aqui da acepção do termo político como instância de conflito, de ruptura e também de criação: de novas formas, tempos e espaços, vínculos e sentidos sociais.

Já o âmbito das políticas culturais tem sido relativamente pouco trabalhado na academia. $\mathrm{Na}$ ciência política crítica, pouco se falou sobre este âmbito da organização da vida em sociedade. Do outro lado, desde os campos da antropologia, da arte e da estética, também são poucos os cruzamentos que se produzem entre a cultura e sua determinação desde instancias institucionais. Em geral, os objetos das políticas culturais estatais são as criações artísticas e/ou culturais: estas entendidas como uma forma específica de um processo social mais amplo; uma manifestação da cultura que envolve um criador, uma obra e um receptor tomando-se em conta as relações não lineares entre estes três momentos, amplamente discutidos principalmente por teóricos da comunicação. ${ }^{5}$ No entanto, este nos parece um terreno fértil para a reflexão, considerando a tensão insolúvel de reconhecer um sistema institucional que se edifica a partir de interesses econômicos e políticos do próprio circuito artístico e da sociedade em seu conjunto e que origina "uma série de políticas públicas, e portanto, formas de legitimação de instâncias e de atores sociais, públicos ou privados, envolvidos no desenvolvimento dos circuitos que os conformam" (Ejea M., T., em Bolán, 2015: 77). Ou seja, com as políticas culturais estatais, inevitavelmente se efetua um recorte sobre o que é ou não é arte e cultura, quais grupos são legitimados para produzi-las, em quais espaços são colocados em circulação etc.

Assim, buscamos neste trabalho complementar a reflexão já existente sobre as políticas culturais estatais brasileiras, desde uma posição que não deixa de considerar os avanços que se deram desde a chegada do Partido dos Trabalhadores na presidência da república, mas que

\footnotetext{
${ }^{5}$ Ver Umberto Eco, Obra Aberta e Interpretação e Superinterpretação; e Roland Barthes, Mitologías.
} 
tampouco se deixa deslumbrar pelos caminhos tomados pelos emblemáticos governos de Lula da Silva e de Dilma Rousseff de 2003 a 2016. Estes estão incluídos no que geralmente se define como "os governos progressistas da América Latina” dos últimos 15 anos, período em que os governos do PT transcorreram sobre premissas e ações não pouco controversas, mas que, no entanto, chamaram a atenção e serviram de inspiração a outros governos latinoamericanos, devido à - entre outros - posição que o Brasil ocupa como potência no subcontinente.

Para tal reflexão, partimos de duas premissas: consideramos que um determinado tipo de política cultural direciona e permite, como tendência, um tipo específico de proposta artísticocultural; e roçando a chamada "função comunicativa da cultura", aqui conferimos à arte e à cultura uma participação primordial e privilegiada nos processos de construção de sentido sobre o mundo social e, portanto, como um espaço para se desafiar a naturalização e a indiferença com relação a esta realidade. Assim sendo, nos perguntamos pela qualidade das produções artístico-culturais financiadas via Lei Rouanet, desconfiados de que a subordinação dos projetos aos critérios privados das empresas financiadoras incorrem em modificações concretas em suas formas e conteúdos - e também convencidos de que estes critérios, na maioria dos casos, são incompatíveis com uma produção e consumo culturais abrangentes e democráticos.

Em breves palavras, buscamos evidenciar algumas decorrências desta política nas propostas artístico-culturais. Evidenciamos algumas consequências negativas desta forma de financiar a cultura, incluindo aí críticas já conhecidas à Lei, mas também somando reflexões com relação aos elementos das propostas que parecem ser mais sensíveis às demandas de mercado. Também apontamos para alguns caminhos de análise crítica do âmbito cultural brasileiro, sem ambição de repensar e propor uma nova política cultural no país, tarefa que ultrapassa em muito as possibilidades deste trabalho. Acreditamos, no entanto, que a reflexão que trazemos aqui sobre o modelo atual agrega elementos pouco discutidos, mas de fundamental importância para o cumprimento daquela tarefa.

\section{Opção teórico-metodológica}

Com relação às opções teórico-metodológicas para a realização deste trabalho, nos limitamos a elucidar que na pesquisa integral de mestrado, que serviu de base a este breve artigo, nos apoiamos em uma perspectiva interdisciplinar, tomando de entrada a dimensão cultural como imbricada no âmbito político da vida social - proposta central dos Estudos Culturais britânicos e suas derivações - e fazendo uso teórico-metodológico da sociologia da arte e da 
cultura e da teoria crítica latino-americana. Além da análise de fontes primárias oficiais, nos apoiamos em entrevistas realizadas com produtores artístico-culturais brasileiros para disparar reflexões pertinentes e conhecer parte do cotidiano daqueles que escolhem ou não buscar financiamento por esta via para manterem-se materialmente ao passo que produzem arte e cultura.

Estes entrevistados atuam, principalmente, nas áreas do audiovisual e das artes cênicas e nossos encontros se deram entre os meses de março e abril de 2016, com produtores culturais que trabalham nos estados de São Paulo, Rio de Janeiro, Santa Catarina, Pernambuco e Ceará. Este recorte se deu, em parte, devido ao tipo de fenômeno que queríamos observar e à aproximação teórica que quisemos dar à questão; mas também pela limitação de tempo e recursos, inerentes a uma investigação de mestrado nos moldes atuais.

\section{Lei Rouanet em números}

Ainda que neste artigo nos dediquemos mais a análises qualitativas, faz-se necessário ao menos mencionar alguns dados numéricos que embasam algumas críticas já conhecidas sobre a operação da Lei Rouanet, conseguidos principalmente através do SalicNet. Esta é basicamente uma bases de dados oficial online onde se publicam informações sobre os projetos que buscam ou buscaram financiamento via Lei Rouanet; também constam informações sobre os candidatos ao apoio financeiro, os financiadores, as quantidades e o caráter dos projetos e dos apoios, entre outros. Para ilustrar a ordem de grandeza dos números que orbitam a operação da Lei Rouanet no período analisado (2003 a 2013), apresentamos alguns deles por meio de duas tabelas, e mencionamos alguns outros ao longo do texto.

De início, parece-nos pertinente comparar os gastos realizados pelo MinC, que são direcionados à sua gestão interna e a todas as 7 autarquias e fundações mantidas por ele ${ }^{6}$, e a quantidade de recursos que são direcionados a projetos via renúncia fiscal da Lei Rouanet (Tabela 1). Chama a atenção que os recursos do MinC, para a maioria dos período, é inferior ao aplicado via renúncia fiscal: até 2007 , foi quase a metade do destinado à Lei Rouanet. É apenas a partir de 2012 que os dois orçamentos quase se igualam, devido a um maior crescimento do orçamento do MinC (Tabela 1).

$\mathrm{Na}$ comparação entre o financiamento direto via Fundo Nacional da Cultura (FNC) e aqueles recursos executados via Lei Rouanet (Tabela 1), se evidencia a grande desproporcionalidade

\footnotetext{
${ }^{6}$ Fundação Biblioteca Nacional (FBN), Fundação Casa de Rui Barbosa (FCRB), Fundação Cultural Palmares (FCP), Fundação Nacional das Artes (Funarte), Instituto de Patrimônio Histórico e Artístico Nacional (Iphan), Agência Nacional do Cinema (Ancine), Instituto Brasileiro de Museus (Ibram).
} 
entre estas duas vias. Para a maioria dos anos do período, os recursos gastos via renúncia fiscal foram, no mínimo, 10 vezes maior que aqueles gastos com o Fundo Nacional da Cultura. Estes valores indicam que, apesar do aumento de recursos direcionados ao MinC, a forma de financiamento indireto (via renúncia fiscal) ainda prevalece com relação àquela de financiamento direto (via Fundo Nacional da Cultura, por exemplo). ${ }^{7}$

Tabela 1 - Relação dos gastos realizados pelo MinC, via Lei Rouanet e via FNC, de 2003 a 2013 , em R\$

\begin{tabular}{|c|c|c|c|c|c|}
\hline & $\begin{array}{r}\text { [A] Gastos Realizados pelo } \\
\text { MinC }\end{array}$ & $\begin{array}{r}\text { [B] Gastos realizados via } \\
\text { renúncia fiscal - Lei } \\
\text { Rouanet }\end{array}$ & $\begin{array}{r}\text { [C] Gastos realizados via } \\
\text { Fundo Nacional da } \\
\text { Cultura (FNC) }\end{array}$ & $\begin{array}{r}{[\mathbf{B}] /[\mathbf{A}]} \\
\%\end{array}$ & $\begin{array}{r}{[\mathbf{B}] /[\mathrm{C}]} \\
\%\end{array}$ \\
\hline 2003 & ------------------ & 430.893 .947 & ----------------- & ----- & ---- \\
\hline 2004 & 266.144 .189 & 511.763 .572 & 16.171 .812 & 1,92 & 31,65 \\
\hline 2005 & 324.058 .719 & 726.779 .080 & 26.011 .775 & 2,24 & 27,94 \\
\hline 2006 & 407.523 .430 & 854.467 .419 & 14.428 .071 & 2,10 & 59,22 \\
\hline 2007 & 470.183 .649 & 990.167 .303 & 25.305 .027 & 2,11 & 39,13 \\
\hline 2008 & 599.431 .768 & 963.700 .957 & 21.635 .312 & 1,61 & 44,54 \\
\hline 2009 & 786.649 .836 & 980.027 .962 & 47.900 .913 & 1,25 & 20,46 \\
\hline 2010 & 749.051 .840 & 1.166 .377 .224 & 47.261.326 & 1,56 & 24,68 \\
\hline 2011 & 946.194 .765 & 1.324 .357 .027 & 51.774 .384 & 1,40 & 25,58 \\
\hline 2012 & 1.093 .275 .966 & 1.277 .060 .885 & 25.077 .005 & 1,17 & 50,93 \\
\hline 2013 & 1.276 .651 .471 & 1.261 .692 .017 & 20.320 .860 & 0,99 & 62,09 \\
\hline
\end{tabular}

${ }^{7}$ Consideramos aqui que há uma forma específica de dividir os gastos em cultura: financiamento direto e indireto, onde o direto é aquele que provem de fundos públicos e que são aplicados diretamente pelo Estado na ação cultural; indireto aquele que também provem de recursos públicos, mas que no entanto são aplicados segundo critérios e decisões do setor privado. Como cada um destes caminhos implica uma forma completamente distinta de proceder por parte dos proponentes, coincidimos com Villalta (2015: 50), quando afirma que "saber que cada forma de financiamento induzirá um tipo de atividade cultural implica assumir que cada modo de financiar o setor da cultura promoverá determinadas características e transformações nos aspectos dos agentes culturais", e agregamos, em nosso caso, também nas criações artísticas. 
Fonte: Portal da Transparência (Despesas - pagamento / Gastos Diretos do Governo / por Órgão Executor), SalicNet e Serviço de informação ao cidadão, protocolo 01590000968201671 respondido em 1 de setembro de 2016. Elaboração Própria. ${ }^{8}$

Para se ter ideia da ordem de grandeza dos projetos, nas áreas de audiovisual e artes cênicas, os maiores projetos anuais captam algo entre 4, 5, 7 até 10 milhões de reais cada, enquanto os menores não passam de poucos milhares de captação (algo entre 1 e 3 mil reais para os projetos em artes cênicas e 4, 5 ou 6 mil para os de audiovisual). É importante também mencionar alguns números que ilustram alguns problemas já bastante conhecidos sobre a forma de operação da Lei Rouanet, todos caracterizados por concentrações de algum tipo.

A começar pela concentração geográfica: para o período analisado (2003-2013), o número de projetos captados por região geográfica do país foram, em proporção: 66\% para a região Sudeste, $21 \%$ para o Sul, $1 \%$ para o Norte, $8 \%$ para o Nordeste e $4 \%$ para o Centro-oeste. Influem nesta concentração alguns fatores como a concentração de renda e de empresas por região brasileira e a distribuição de equipamentos culturais. Há também um tipo de concentração com relação às áreas culturais contempladas pela Lei Rouanet e, ainda que não possamos aqui tratar os pormenores deste problema, mencionamos apenas que as áreas e segmentos culturais tratados nesta lei são agrupados ao redor das "categorias" Artigo $18^{9} \mathrm{e}$ Artigo 26. Cada um desses artigos incorrem em benefícios fiscais diferenciados para os patrocinadores e esta diferenciação foi criada em 1999 a partir de uma compreensão de que algumas áreas mereciam mais apoio e recursos que outras. No entanto, esta mesma diferenciação incorreu em novas concentrações. Para o período analisado, $93 \%$ dos projetos se enquadraram no Artigo 18 e $7 \%$ no Artigo 26.

Por fim, há também a concentração com relação aos grandes proponentes. Segundo

\footnotetext{
${ }^{8}$ Portal da Transparência: http://www.transparencia.gov.br

SalicNet: http://sistemas.cultura.gov.br/salicnet/Salicnet/Salicnet.php

Sistema eletrônico do Serviço de Informação ao Cidadão:

https://esic.cgu.gov.br/sistema/site/index.aspx
}

\footnotetext{
${ }^{9}$ As áreas ou segmentos culturais contemplados pelo Artigo 18 são: a área de artes cênicas completa e os segmentos de música erudita e instrumental, exposição de artes visuais, construção e manutenção de salas de cinema e teatros em municípios com menos de 100 mil habitantes, livros de valor artístico, literário ou humanístico, doações de acervos para bibliotecas, museus ou arquivos, preservação de patrimônio cultural material e imaterial, produção de obras cinematográficas e videofonográficas de curta ou longa metragem e preservação e difusão de acervo audiovisual.
} 
informações do MinC, 3\% dos proponentes captam em torno de $50 \%$ dos recursos. ${ }^{10}$ Mencionamos alguns dos proponentes que figuraram entre os 15 maiores em todos ou quase todos os anos do período analisado: Instituto Itaú Cultural, Fundação Orquestra Sinfônica Brasileira, Fundação Roberto Marinho, Fundação Padre Anchieta, Museu de Arte Moderna de São Paulo (MAM), Instituto Tomei Ohtake, Associação Pinacoteca Arte e Cultura (APAC), Instituto Alfa de Cultura, Time for Fun, Divina Comédia Promoções Artísticas Ltda., Dell Arte Soluções Culturais Ltda. etc.

Já com relação às quantidades de projetos, a partir de 2007, havia ao ano entre 3041 e 3750 projetos em captação, dos quais uma média de 1300 eram finalizados anualmente (Tabela 2). É importante mencionar que há uma discrepância entre o número de projetos captados e finalizados ao ano pois o prazo previsto em lei para a captação é de 24 meses, com possibilidade de algumas exceções que permitem a extensão deste prazo ainda mais, de forma que há muitos casos nos quais ditos projetos são contabilizados como "captados" por dois ou mais anos consecutivos. Assim, ainda que na tabela conste, na maioria dos anos, que a proporção de projetos captados em relação aos aprovados seja de, em média, 46\%, sabemos que esta proporção é inclusive mais baixa (Tabela 2). Segundo Alexandra Costa, do MinC, "a média histórica de captação com relação à aprovação é de $25 \%$ ou $27 \%$ ".

Tabela 2 - Quantidade de projetos que concorreram na Lei Rouanet, de 2003 a 2013

\begin{tabular}{llllll}
\hline & apresentados A & aprovados B & captados C & B/A \% & C/B \% \\
\hline $\mathbf{2 0 0 3}$ & 5258 & 4069 & 1543 & 77 & 38 \\
\hline $\mathbf{2 0 0 4}$ & 6227 & 4958 & 2040 & 80 & 41 \\
\hline $\mathbf{2 0 0 5}$ & 10315 & 5990 & 2476 & 58 & 41 \\
\hline $\mathbf{2 0 0 6}$ & 8756 & 6533 & 2929 & 75 & 45 \\
\hline $\mathbf{2 0 0 7}$ & 10903 & 6358 & 3232 & 58 & 51 \\
\hline $\mathbf{2 0 0 8}$ & 9494 & 6874 & 3163 & 72 & 46 \\
\hline $\mathbf{2 0 0 9}$ & 6970 & 4731 & 3041 & 68 & 64 \\
\hline $\mathbf{2 0 1 0}$ & 8807 & 7361 & 3417 & 84 & 46 \\
\hline $\mathbf{2 0 1 1}$ & 8325 & 7751 & 3750 & 93 & 48 \\
\hline $\mathbf{2 0 1 2}$ & 6083 & 6347 & 3585 & 348 & 104 \\
\hline $\mathbf{2 0 1 3}$ & 6863 & 6442 & 3480 & 54 & 54 \\
\hline
\end{tabular}

Fonte: SalicNet (Comparativos / Quantitativos / Mecenato). Elaboração própria.

\section{A Lei Rouanet e as Relações de poder no Estado brasileiro}

\footnotetext{
${ }^{10}$ Segundo consta no item 9 da carta dirigida ao presidente da república, anexada ao Projetos de Lei 6.722/2010 - Procultura.
} 
Relembramos aqui que o funcionamento deste mecanismo de financiamento a projetos culturais, na prática, envolve três atores sociais fundamentais: os criadores das propostas artístico-culturais (ou proponentes), o Estado brasileiro (que aparece, neste caso, na figura institucional do MinC) e as empresas financiadoras - em sua maioria, privadas. As relações que se dão entre estes três estão inseridas em um campo de poder, que aparece de forma explícita ou implícita, dependendo da mirada que se lance à questão. Por exemplo, se percorremos linearmente o trajeto tomado para que um projeto artístico-cultural seja concretizado por esta via, algumas relações de poder aparecem de forma mais evidente: num primeiro momento, o Estado aprova ou reprova a proposta artístico-cultura - desta forma, queira ou não queira, está definindo (ainda que momentaneamente) o que é ou o que não é uma proposta cultural e quais delas valem a pena serem concretizadas. Num segundo momento, ainda mais determinante para a sua concretização - como veremos -, o possível patrocinador possui a prerrogativa de decidir quais deles poderão ser executados, pois aceita ou não financiar a proposta. Por esta mesma vereda, poderíamos pensar ademais em outras configurações onde se fazem evidentes as relações de poder, a possível "vantagem" de uns frente a outros: grupos ou artistas que dominam a técnica de objetivação de uma proposta artístico-cultural em forma de projeto e os que não a dominam; grupos ou artistas que apresentam propostas mais facilmente aceitas em meio aos discursos sociais vigentes e os que apresentam propostas mais polêmicas ou que questionam o status quo; grupos ou artistas que estão localizados em regiões do país que contam com mais recursos humanos, técnicos e de infraestrutura, e os que estão localizados em periferias com infraestrutura e recursos precários etc.

Apesar de que uma maioria de projetos é aprovada pelo MinC, a grande maioria não é executada devido ao rechaço da empresa financiadora. Daí a constatação de que um dos grandes obstáculos, se não o maior, para a concreção das propostas artístico-culturais está no poder de decisão das empresas, nos levando a indagar sobre o papel que jogam estas mesmas empresas no direcionamento da produção cultural hoje no Brasil. Sabemos que os interesses e motivações que movem a atuação das empresas privadas, em última análise, são a geração de lucro que, trazendo ao caso concreto do patrocínio cultural, se expressa nas estratégias de marketing para fortalecer suas marcas, para conquistar novos consumidores - ampliando sua participação no mercado.

Trata-se de uma disposição de dinheiro público em função de interesses privados, pois são recursos provindos, principalmente, dos impostos sobre a renda devidos ao Estado distribuídos segundo critérios particulares do patrocinador, deixando patente a associação, 
ainda que pouco visível num primeiro momento, entre as empresas privadas e o Estado - que, a final de contas, mesmo que aparentemente possuindo os meios e o poder para modificar radicalmente esta relação, não o faz, "deixando" com que seja o setor privado que decida o destino dos recursos públicos para a cultura.

As chaves interpretativas para examinar esta associação entre o Estado e o setor privado no Brasil podem ser buscadas na recuperação do fenômeno de mundialização da economia sob o substrato ideológico e político do neoliberalismo, a partir das décadas de 70 e 80 , com a consequente diminuição da soberania dos Estados latino-americanos e de outros países periféricos - que no trabalho de mestrado buscamos em autores como Jaime Osorio e Wilson Cano. ${ }^{11}$ Não cabe no espaço deste artigo aprofundar na forma como estes Estados foram perdendo soberania, ao passo que empresas multinacionais iam ganhando mais poder político e econômico ao redor do globo. Nos interessa ressaltar, no entanto, a persistência do papel preponderante que cumprem ainda hoje as empresas nacionais e multinacionais no Brasil na condução desta forma de desenvolvimento que vivemos hoje no país - e aí incluída a forma de se produzir arte e cultura.

Ainda, é importante olhar para este momento histórico (das décadas de 70 e 80) como aquele que possibilitou que se configurasse um tipo de aparato estatal que deu lugar ao surgimento e à manutenção de leis e normas como a Lei Rouanet - em que o Estado permite e até facilita legalmente e institucionalmente a atuação das empresas segundo seus próprios interesses, em diversas áreas sociais. Wu (2006), ao analisar o fenômeno da privatização da cultura, centrando-se nas experiências britânica e estadunidense, chama a atenção para um fato importante, e que deve ser objeto de permanente desmistificação em nossas sociedades ainda hoje em dia: ao contrário do que se poderia pensar, o livre-mercado e o subsídio estatal sempre caminharam juntos. O protagonismo das empresas na organização da vida econômica, política, científica, produtiva, social e cultural se dá, somente, com um massivo e imprescindível apoio político, institucional e financeiro do mesmo Estado a este setor, fazendo "uso do dinheiro público para aumentar as prerrogativas do capital privado" (Wu, 2006: 30).

\footnotetext{
${ }^{11}$ Ainda que os dois autores não sigam exatamente a mesma linha, ambos constroem suas ideias a partir de uma postura crítica às teorias econômicas clássicas e de corte neoliberal. Ambos possuem trabalhos consistentes que tratam sobre a conformação e as características dos Estados de países periféricos a partir do processo de mundialização da economia. As ideias de Wilson Cano estão vinculadas a Escola de Economia da Unicamp, enquanto as de Jaime Osorio seguem a Teoria Marxista da Dependência.
} 
Este pequeno "desvio" histórico entre os processos econômicos e políticos mundiais que plasmamos aqui não é ocioso, pois nos permite elucidar pelo menos alguns pontos: 1) ao contrário de olhar o Estado como uma entidade que neste momento histórico está perdendo poder frente à sociedade, que está se ausentando ou diminuindo de tamanho, devemos recordar o papel ativo que joga o Estado para permitir que as empresas se estabeleçam e defendam seus interesses em territórios nacionais: mais do que um Estado pequeno, temos hoje um Estado reconfigurado que, ainda que se ausente na atuação direta em vários setores produtivos e sociais, prepara o caminho e provê todo o substrato legal, institucional e financeiro para que as empresas privadas passem a atuar nos vazios deixados pelo "Estado grande", ou o "Estado de bem-estar"; 2) as classes dominantes no Brasil (que estão constituídas por detentores de grandes empresas transnacionais ou estreitamente vinculadas com o capital estrangeiro) são as que pressionam e em grande medida direcionam a conformação do aparato estatal para que seus interesses prevaleçam sobre os interesses comuns. Sobre isso, Osorio (2014: 158, tradução nossa) esclarece: "tanto no mundo imperialista como na periferia, os que detêm o poder se atrincheiram no Estado, fazendo com que seus interesses possam apresentar-se como interesses "da nação", quando não da humanidade, e potencializar desde lá sua força para impulsioná-los”.

\section{Cultura como construtora de sentido e a análise de uma obra}

Antes de abordar mais especificamente o impacto desta política cultural nas propostas artístico-culturais que dela participa, gostaríamos de introduzir brevemente alguns elementos a serem considerados numa tarefa deste tipo, com o objetivo de defender a pertinência do tema e apontar caminhos para futuras pesquisas. Trata-se, afinal de contas, de uma reflexão inscrita no âmbito da crítica da arte e da cultura - o que nos possibilita buscar nas teorias da comunicação, na sociologia da arte e da cultura, e na chamada teoria crítica latino-americana mais variáveis que ajudam a enriquecer a tarefa.

Sugerimos, de saída, que o espaço de análise destas propostas deve ultrapassar a trama textual da obra em si, e tomar como fundamental também o que a rodeia, seu contexto social, como por exemplo: qual tipo de relação artista - obra - receptor se está propondo, qual materialidade artística, os espaços de apresentação utilizados, o público buscado, os intermediários, as instituições envolvidas e demais elementos que orbitam o processo artístico, mostrando-nos, com isso, pistas sobre quais tipos de experiências comunicativas podem estar gerando em seus receptores estas produções simbólicas.

Para esta tarefa, neste trabalho, nos interessa resgatar brevemente a dimensão da cultura como 
partícipe dos processos de construção social de sentido - ou seja, estamos adentrando a chamada função comunicativa da cultura, recuperando-a como dimensão da vida que pode induzir, ou ao menos conferir, sentido aos acontecimentos históricos; que matiza de forma determinante a maneira em que um indivíduo entende, interpreta, atua e gera conhecimento sobre sua própria realidade e imagina uma realidade diferente; como uma das dimensões que influem nas formas dos vínculos sociais. ${ }^{12}$

Fazem parte do processo de construção social de sentido objetos, pessoas, o sistema escrito e falado, gestos, imagens visuais, sons; e expressões artísticas - ou formas culturais - tais como uma música, uma obra de teatro, um filme, uma instalação artística, entre tantos outros eventos e fatos sociais gerados por pessoas localizadas espacial e historicamente, que pertencem a uma determinada classe, etnia, gênero; com vivencias pessoais distintas, em posições de poder distintas. Toda essa articulação textual ou discursiva forma um mapa de significados que participa da trama de sentido para o mundo.

Este recorte sobre a função comunicativa da cultura também implica tomar a arte não como um objeto de pura contemplação, senão como um gesto artístico, simbólico e político que pertence a um contexto social. ${ }^{13}$ Daí a pertinência de se pensar sobre os elementos constitutivos das propostas, sua qualidade, suas formas e conteúdos ${ }^{14}$ e demais elementos que a constituem.

Nos parece, no entanto, que o tema da qualidade (no sentido de características) das obras derivadas da Lei Rouanet, seus elementos mais sensíveis aos condicionamentos do mercado e as consequências sociais desta dinâmica não estão no centro da reflexão dos trabalhadores da cultura: seja devido às exigências da "luta diária pela sobrevivência", seja pelos "vícios de debate" que centralizaram as discussões dos criadores e produtores nos últimos anos em

${ }^{12}$ Para tratar esse assunto, nos apoiamos em Stuart Hall, Roland Barthes, Umberto Eco e Bolívar Echeverría.

${ }^{13}$ Néstor García Canclini, em sua obra "La Producción Simbólica" de 1979 - onde se faz presente um espirito crítico que segundo nossa perspectiva se ausenta em seus trabalhos mais recentes - dá conta da genealogia, dos desafios e das principais linhas teóricas e metodológicas para pensar-se a construção social do imaginário, a arte na sociedade e os efeitos de esta última vinculação sobre o campo estético.

${ }^{14}$ Esclarecemos aqui que vemos estes dois âmbitos, a forma e o conteúdo dos projetos, como um amálgama, duas dimensões que estão soldadas e que, como bem aponta Canclini (2014: 84), podem entrar em contradição. Ambos participam em igual medida na construção de significações: tanto os conteúdos iconográficos das obras, seu texto, sua plástica, suas temáticas, etc.; quanto a maneira como se apresenta a obra: os códigos não linguísticos, os estilos cinematográficos, musicais, teatrais, o tipo de interação proposta com o público, o tipo de espaço onde se insere (galerias, casas de espetáculos, praças públicas etc.). 
problemas sobre a gestão de recursos e o volume de financiamento da cultura, e não na discussão sobre que tipos de produções se dão hoje no Brasil e para onde estamos caminhando nesse cenário, que implicaria também, em algum momento, uma discussão e articulação de um amplo projeto para a cultura do país - que envolve, sem lugar a dúvidas, uma reflexão a respeito do tipo de produção artístico-cultural que seria mais produtivo (no sentido de potencialidade transformadora) para este momento histórico na sociedade brasileira.

Refletir criticamente sobre a cultura neste país, neste momento histórico, também exigiria a tarefa de ir além de uma reflexão que se restrinja à formação cultural brasileira, para também pensar sobre o papel e posição que ocupa o Brasil hoje no mundo e, desta forma, questionar sobre as condicionantes estruturais e processuais que determinam ou influenciam nossa forma de produzir, distribuir, consumir - em outras palavras, nos relacionarmos com - arte e cultura, considerando que nosso imaginário e visão de mundo estão influenciados pelas assimetrias nas correlações de forças que se dão entre as nações. Isto é, faz-se necessário um comprometimento com a postura epistemológica que considera o Brasil e a América Latina em suas especificidades e determinações, tendo em vista o lugar destes países na economia política internacional, considerando a seu passado colonial não como um mero antecedente, mas sim como um ponto de partida completamente distinto do de outros países centrais. Para tanto, há que recuperar algumas contribuições da teoria crítica latino-americana que abordam temas como a dependência político-econômica, o colonialismo cultural, a colonialidade do poder e o imperialismo cultural estadunidense ${ }^{15}$; bem como esboçar de forma mais esmerada as mediações existentes entre estes processos, o papel que cumprem as empresas multinacionais em solos latino-americanos, onde se situam e como se relacionam com as políticas culturais, suas condicionantes e, por fim, que tipo de produção cultural é privilegiada por um mecanismo tal como a Lei Rouanet, que obedece às leis de mercado.

\subsection{Três aspectos sobre as propostas}

Neste caso, vamos nos dedicar exclusivamente a uma questão específica, mas que se encontra

\footnotetext{
15 Alguns autores preferem reservar o conceito colonialismo para o período histórico, circunscrito espacialmente, que se refere à ocupação colonial ibérica na América Latina ou outros processos coloniais recentes em diversos países africanos e asiáticos; propondo em contrapartida o conceito de pós-colonialismo ou de colonialidade para tratar das sequelas e impactos destes processos históricos no presente. Por outro lado, cabe perguntar se estes três conceitos - como questiona Gómez Arredondo (2014: 32) - teriam alcance explicativo para dar conta da estrutura atual do padrão de poder mundial, que sem dúvidas incorpora o papel preponderante e imperialista dos Estados Unidos no último século.
} 
submersa nesta "rede" de temas: pensar sobre algumas características das obras que se submeteram às regras da Lei Rouanet para se concretizarem. Se bem os resultados tratados aqui não são conclusivos, há fortes evidências de que há um padrão de propostas artísticoculturais privilegiado por esta lei, por esta forma de incentivar e financiar a produção cultural no Brasil -que, indubitavelmente, não é a única possível. E, ainda que certamente há projetos que fujam a este padrão, nos parece importante esboçar a tendência predominante nesta forma de financiar arte e cultura.

Assim, nos guiamos por perguntas sobre qual padrão de poder a Lei Rouanet privilegia hoje, sobre se esta política reforça as estruturas de poder dominantes que condicionam nossa realidade social, para adentrar alguns elementos das propostas que estão mais condicionados à racionalidade mercantil que guia sua operação. Para tal aproximação, nos baseamos nas percepções e experiências dos entrevistados ${ }^{16}$, assim como em outros documentos onde constam mais informações sobre as propostas e os proponentes. Algumas perguntas-guias utilizadas na reflexão e derivadas, em outras palavras, nas entrevistas foram: os artistas e produtores condicionam suas criações aos interesses do mercado? Esta preocupação com o vendável está presente desde o momento de concepção da obra? O mais facilmente vendável expressa, na maioria dos casos, uma conformidade com o status quo, com os discursos hegemônicos sobre aspectos de nossa realidade? Os proponentes se dão conta destes condicionamentos? Como se objetivam os parâmetros mercadológicos em uma proposta artístico- cultural?

Com estes temas em mente, um adendo: consideramos impossível utilizar deste curto espaço para citar textualmente trechos das entrevistas. Por conseguinte, faremos uma síntese de três

\footnotetext{
${ }^{16}$ Foram entrevistados nesta pesquisa de mestrado: Alexandra Luciana Costa, então Diretora de Incentivo à Cultura, vinculada à Secretaria de Fomento e Incentivo à Cultura (SEFIC) do MinC; Kiwi Companhia de Teatro, dedicado ao teatro de grupo, atuantes em São Paulo principalmente; Ney Piacentini, ator e pesquisador da Companhia do Latão e ex-presidente da Cooperativa Paulista de Teatro; Instituto Alta de Cultura, que leva em seu nome a marca da corporação Alfa, que atua nos segmentos financeiro, agroindustrial, alimentício etc.; Centro de Cultura, Informação e Meio Ambiente (CIMA), do Rio de Janeiro, que realiza o Festival do Rio, de cinema; Florianópolis Audiovisual Mercosul (FAM), festival de cinema de Florianópolis-SC, do qual o proponente é a Associação Cultural Panvision; Cine Ceará, festival de cinema de Fortaleza, do qual o proponente é a Associação Cultural Cine Ceará; Grupo Anônimo de Teatro, do Rio de Janeiro, da tradição do teatro de rua; Pedro Vilela, trabalhador do teatro de Recife - PE, ex-integrante do grupo teatral Magiluth e atual idealizador e produtor da TREMA!, plataforma que congrega coletivos de teatro de grupo; Mostra do Filme Livre, festival de cinema para a exibição de obras brasileiras de curta, media e longametragem realizados de forma independente; Janeiro de Grandes Espetáculos, festival de teatro da cidade de Recife -PE.
} 
pontos principais, pertinentes a este escopo, onde constam resultados de entrevistas combinados com reflexões próprias.

a) os artistas adequam seus projetos às ideias das empresas patrocinadoras. Frequentemente não se toca em temas "polêmicos".

Alguns entrevistados forneceram declarações muito relevantes com relação ao conteúdo dos projetos e restrições imaginadas de antemão ou explicitamente exigidas pelos patrocinadores, como por exemplo o caso de mudança de texto de uma obra de teatro devido a uma solicitação do patrocinador ou a afirmação de que há retração de mercado com relação a certos conteúdos - ou seja, uma ponderação na criação, dependendo de com quem se buscará associar.

Ainda que não tenhamos podido apreender concretamente os elementos materiais ou textuais das propostas que são problemáticos aos "olhos" (necessidades e valores) das empresas financiadoras, resultou evidente nas entrevistas que o acordo possível entre as duas partes implica uma desvinculação com o polêmico. O polêmico na linguagem corrente se refere ao controverso, o conflitivo, o que planta a discórdia, ao que gera uma multiplicidade de opiniões não necessariamente concordantes. Acreditamos que, em geral, em nossa sociedade se atribui ao conflitivo um sentido negativo: o relacionamos com o violento, o destrutivo, às rupturas definitivas, colocando de lado - convenientemente - sua dimensão construtiva, geradora de novas ideias e que historicamente possibilitou saltos civilizatórios. O polêmico, o conflitivo é um espaço privilegiado para a política, onde se dão disputas de sentido, de direção, de construção de novas formas sociais. Uma produção artístico-cultural que trata de desvincular-se em todos os seus âmbitos do conflitivo, que busca estar em conformidade com o já estabelecido, parece estar em busca de um suposto status neutro que, teoricamente, serviria para entreter um público esvaziado de capacidade crítica, passivo, não participante dos processos de significação da obra.

Assim, nos parece que propostas artístico-culturais que apresentem uma ruptura muito explícita com o sentido comum ou com o discurso social estabelecido - em outras palavras, que apresentem uma "polêmica" facilmente notável -, em qualquer dos âmbitos que as constituem e que já tratamos aqui, encontrariam muito mais dificuldades para serem financiadas por meio do caminho típico de venda de um projeto a uma grande empresa privada.

b) recorte de classe no público dos grandes projetos patrocinados pela Lei Rouanet. 
Consideramos que o recorte de classe no público dos projetos pode se dar devido a alguns fatores, a saber: a cobrança de ingresso, a localização geográfica dos equipamentos culturais utilizados, a linguagem artística utilizada, o serviço de transporte público existente, entre outros. Constata-se pelo SalicNet que os maiores projetos anuais são temporadas de dança ou teatro, musicais e exposições de artes visuais, que se dão por meio de cobrança de ingresso muitas vezes com valores bastante altos ou, quando gratuitos, geralmente apresentados em equipamentos culturais localizados em zonas nobres das cidades.

Ilustramos a questão com uma simples menção, nada exaustiva, à localização geográfica de equipamentos de grandes proponentes como:

i) Teatro Alfa (do Instituto Alfa de Cultura): bairro Santo Amaro em São Paulo, público-alvo de classe A e B;

ii) Time for fun: proponentes que comumente utiliza equipamentos como o Citibank Hall, também em Santo Amaro, o Teatro Renault - no bairro República, parte relativamente nobre do centro de São Paulo, o Metropolitam, no bairro nobre da Barra da Tijuca no Rio de Janeiro e o Chevrolet Hall no bairro nobre da Savassi em Belo Horizonte;

iii) Itaú Cultural, que ainda que ofereça o aceso à maioria de suas atividades de maneira gratuita ou a preços baixos, está localizado na emblemática e nobre Avenida Paulista: centro financeiro e zona turística da cidade de São Paulo.

O espaço utilizado para a apresentação de uma obra é uma variável que influi sobremaneira no tipo de relação obra/público que se conseguirá, portanto é uma escolha política da maior importância. Os maiores projetos apoiados via Lei Rouanet são apresentados em teatros tradicionais, localizados em zonas nobres da cidade ou em grandes museus - espaços historicamente legitimadores de obras de arte e segregadores, em que pese sua importância. Ainda que estes projetos incorporem as medidas de democratização do acesso estipulados em lei, não podemos deixar de remarcar o recorte de público que esta política cultural está realizando, como tendência.

c) os musicais: os filhos prósperos da Lei Rouanet.

Trata-se de um segmento que hoje conta com grande potencial de lucro ou com maior possibilidade de auto-sustentar-se, enquadrado nas artes cênicas. Houve um grande crescimento desta área nos últimos 10 anos. Desde 2003, é notável que anualmente entre os 10 maiores projetos financiados via renúncia fiscal, aparece mais de um musical. A maior produtora atuante no Brasil neste segmento é a empresa de capital aberto Time for Fun 
$(\mathrm{T} 4 \mathrm{~F})^{17}$, que se auto-define como líder no ramo de entretenimento ao vivo. Seus projetos de musicais geralmente captam entre $\mathrm{R} \$ 3$ e 13 milhões cada temporada, e na grande maioria das vezes trata-se de grandes êxitos de bilheteria criados e exibidos na Broadway, traduzidos e adaptados ao português. ${ }^{18}$

Não podemos deixar de comentar aqui, dada a pertinência do tema, que um dos produtores que mais capta recursos via renúncia fiscal se dedica à produção de musicais de forma e conteúdo completamente referenciados em suas versões originais, estadunidenses. Não nos parece acertado tecer um juízo moral sobre a qualidade desta obras, no entanto devemos ressaltar nosso incômodo com que uma parte considerável destes recursos públicos esteja destinado a produções com referencial, história, construção e sentido alheios a nossa realidade brasileira. Uma produção estadunidense - ou sua "tradução" - não é o problema, em si mesma; mas quando localizada e posta em relação com o que a rodeia em nossa sociedade pode tornar-se um alerta. Uma ação de governo, uma política pública, deve ser planejada em relação com os demais condicionantes de uma determinada realidade - isto é, uma política pública com a qual se busque impactar o tipo de desenvolvimento de um espaço e povo determinado, deve ser pensada considerando as condições estruturais e contingenciais sobre o terreno, contra as quais há que se "lutar contra". Não existe tal coisa como uma política pública de modelo neutro, que sirva de igual maneira a diversas realidades.

Se no Brasil já estamos submetidos de forma importante às condicionantes de um colonialismo cultural, que se expressa cotidianamente na maioria das salas comerciais de cinema (com suas programações $80 \%$ tomadas por filmes estadunidenses) ${ }^{19}$, nos televisores, repletos de uma programação de séries e filmes de igual procedência (e não brasileiras, latinoamericanas ou asiáticas, por exemplo), que o modelo arquitetônico das grandes cidades é de

17 A Time for Fun, a Aventura Entretenimento - também especializada em musicais -, junto a instituições culturais de grandes empresas privadas (notavelmente o Instituto Itaú Cultural, o Instituto Alfa de Cultura e a Fundação Roberto Marinho) e grandes orquestras encabeçam a lista dos maiores proponentes à Lei Rouanet.

${ }^{18}$ Se destacam: Mamma Mia $\mathrm{R} \$ 12,6$ milhões, Disney on Ice $\mathrm{R} \$ 4,5$ milhões, Cirque du Soleil $\mathrm{R} \$ 9,3$ milhões, Billy Eliot R \$3,5 milhões, O Fantasma da Ópera R \$10,17 milhões, CATs R \$5,42 milhões, O Rei Leão R \$13,51 e R \$14,3 milhões, Jesus Cristo Superestar R \$2,45 milhões, Wicked R \$13,4 milhões.

${ }^{19}$ Segundo Frédéric Martel (2013), o cinema Hollywoodiano ocupa um volume de $80 \%$ das bilheterias no Brasil. 
tendência homogeneizante (com a cara de seus empreendimentos multinacionais, perdendo seus marcos de distinção que logo as faz parecer a qualquer outra grande cidade do mundo) ${ }^{20}$, se as publicidades e textos comunicativos de pequenos e grandes empresas estão repletos de expressões em inglês (como se fosse imperativo a todos os brasileiros que soubessem comunicar-se em inglês tanto quanto em português); enfim, se já estamos rodeados destas produções simbólicas alheias que participam na trama de sentido da nossa realidade, uma política pública que destina um grande volume de recursos em produções musicais nestes moldes não é o que necessitamos - e, provavelmente, sua tendência geral deveria ser justo o contrário. $^{21}$

\subsection{Que padrão a Lei Rouanet privilegia?}

Como consequência desta forma de financiamento, derivam dinâmicas que organizam em grande medida o espaço da produção artístico-cultural no Brasil, que incorre em influências concretas no fazer cultural dos trabalhadores da cultura. Apesar de que os projetos culturais possam ser financiados por pessoas físicas ou empresas estatais ou privadas, constatamos que a grande maioria dos projetos são financiados por empresas privadas, que operacionalizam a Lei Rouanet de uma forma particular ${ }^{22}$, a qual, sem lugar a dúvidas, tende a privilegiar um certo padrão de projetos - genericamente caracterizados como "mais vendáveis" -, de certa dimensão e volume, propostos por um tipo determinado de proponentes (os maiores, mais

20 Sobre o tema dos traços urbanísticos distintivos, carregados de capital simbólico coletivo, transformados em commodities, ver Harvey, David (2001), capítulo VIII pp. 219-239.

${ }^{21}$ Esclarecemos, no entanto, que não nos posicionamos contra a divulgação de produções artísticoculturais estrangeras, especialmente estadunidenses, em território nacional; mas nos parece evidente que não todo conteúdo estrangeiro tem semelhante espaço no Brasil e que, portanto, quando um caso como o da produtora Time for Fun salta aos olhos em uma política pública, é imprescindível fazer a crítica.

${ }^{22}$ Foi possível constatar nesta pesquisa que a forma de se relacionar com a Lei Rouanet e, consequentemente, com os projetos e proponentes, é ligeiramente diferente quando se trata de um financiador empresa estatal ou empresa privada: a forma de se acessar o financiamento, os fins buscados com o apoio e os resultados na sociedade também. Em geral, pequenos projetos ou proponentes têm mais chances de possuir seus projetos financiados por empresas estatais, que operacionalizam a seleção por meio de editais públicos. Por outro lado, constatamos que são pequenas as chances de que um proponente com este mesmo perfil consiga financiamento junto a uma grande empresa privada, que em geral busca projetos de proponentes e elencos mais renomados, de perfil mais "comercial", de alto orçamento etc. Ainda que anualmente aproximadamente 5 empresas estatais figurassem entre os 15 maiores proponentes, é importante dizer que para o período analisado (2003-2013), os recursos investidos por todas as estatais juntas representaram uma média de $27 \%$ dos recursos globais. 
renomados e mais "profissionais"), para um público restringido (seja pela localização geográfica nacional ou municipal dos grandes projetos, seja pelos preços cobrados nos ingressos, seja pelo tipo de proposta). Devido a esta forma de colocar em operação o mecanismo, próprio das empresas privadas, já são de saída observadas consequências negativas notáveis como a concentração geográfica, a concentração nas mãos de alguns proponentes e a concentração em algumas áreas culturais. Ademais das concentrações, as condições de trabalho dos trabalhadores da cultura se tornam marcadas pela instabilidade, a precariedade e a falta de apoio legal. ${ }^{23}$

Os critérios e parâmetros com os quais as empresas avaliam a qualidade dos projetos culturais estão enquadrados em valores e práticas tais como a tecnocracia, a meritocracia, a eficiência, a produtividade, a geração de lucro, a viabilidade comercial, a criatividade subordinada à inovação, etc. O que se busca, assim, são projetos "limpos", com resultados palpáveis, gerenciados de forma profissional, que gerem receita para sustentar-se através de bilheteria, que empregue recursos da forma mais eficiente possível, de pouca ou nenhuma polêmica, onde prevaleçam a técnica sobre o político a nível denotativo da narrativa, que tratem de temas já amplamente aceitos pela maioria da população, entre outros caminhos possíveis para garantir-se que o projeto seja o mais previsível e sem riscos possível.

Até aqui observamos que estas consequências reforçam e reproduzem alguns privilégios e marginalidades já presentes na sociedade brasileira: obedecendo o mesmo padrão de concentração e desenvolvimento regional no Brasil, colocando ainda mais em evidência os atores sociais que já são grandes, visíveis e privilegiados nesta sociedade, agregando cada vez mais a massa de trabalhadores da cultura na parcela da população economicamente ativa dependente de trabalhos informais, com extensas jornadas e escassos direitos trabalhistas. Assim, esta política cultural não ataca as assimetrias das condições de trabalho entre os setores da sociedade, não ataca as assimetrias estruturais entre os grandes, renomados e poderosos atores sociais e os pequenos, mais marginalizados e sem poder.

Com as experiências coletadas, ficou claro que a Lei Rouanet prioriza um tipo de forma cultural produtivista e mercantil, enfocada na criação de um produto, um evento - não em um processo, uma ação cultura. O exemplo paradigmático são os musicais, concebidos como grande produções de muitos estímulos visuais e sonoros, para um público restringido, onde não raro trata-se de assignar ao receptor o papel de simples consumidor, não de produtor

\footnotetext{
${ }^{23}$ Para uma crítica mais completa com relação às consequências da Lei Rouanet no mercado de trabalho cultural, ver Villalta, F. G. (2015)
} 
de sentido e de conhecimento; ademais, o financiamento pensado como estratégia de marketing cultural implica uma série de restrições e preferências.

\section{Considerações finais}

As mediações necessárias para uma aproximação mais esmerada a essas questões não são simples e evidentes, e neste trabalho não apresentamos respostas definitivas a estas indagações. No entanto, acreditamos que com as reflexões derivadas destas entrevistas e demais materiais podemos vislumbrar um tratamento distinto a este "problema da Lei Rouanet", complementar às críticas já existentes e, acreditamos, tocando em questões mais estruturais, as quais serviriam para futuras pesquisas e ofereceriam alguns outros argumentos incipientes para o tema.

Ainda que não tenhamos podido aprofundar teoricamente tanto quanto gostaríamos na questão das consequências da posição periférica do Brasil no âmbito da cultura, esta inquietação estava presente tanto no entendimento sobre o Estado latino-americano, quanto na reflexão sobre as consequências desta política cultural - que tem seu eixo centrado na decisão e direcionamento privado do uso de recursos públicos - nas propostas artístico-culturais.

A atuação profissional dos trabalhadores da cultura historicamente se deu imersa em não poucas tensões e contradições: se, por um lado, numa sociedade organizada sob a lógica de relações mercantis, estes necessitavam recursos econômicos para reproduzir suas vidas materiais como qualquer outro trabalhador, por outro lado seu tipo de atividade acontece mediante processos que apresentam bastante incompatibilidade com a racionalidade mercantil. Se em diversas áreas de atuação profissional já é possível rapidamente observar contradições com as prerrogativas do mercado (tal como na academia e na produção científica, na saúde, no planejamento urbano, entre outros), na área da arte e da cultura algumas contradições ficam ainda mais em evidência: os tempos de desenvolvimento são outros, o produto final nem sempre é um resultado quantificável ou palpável, o tipo de recepção não é linear e objetivo etc.

Porém, como estratégia de sobrevivência, a maioria dos trabalhadores da cultura - os que estão fora das grandes produtoras, emissoras ou gravadoras - tiveram que adaptar-se às possibilidades disponíveis, ao passo que protagonizavam, em alguns momentos mais do que em outros, as disputas pelo direcionamento e o apoio estatal às suas atividades profissionais. Conferindo às dimensões da arte e da cultura seu espaço na trama de objetos e acontecimentos que participam na construção social de sentido para o mundo, também concedemos a estas dimensões uma potencialidade de modificação dos sentidos vigentes, de desnaturalização de 
formas estabelecidas, de questionamento da racionalidade instituída. São espaços privilegiados e que pode fazer uso de outras formas de conhecimento e racionalidades, notavelmente o conhecimento sensível, sensitivo, imaginativo, intuitivo, emocional. Daí que, frente a um mundo que reclama uma transformação radical das formas de reprodução da vida - e que leva o selo/carimbo de uma racionalidade moderna funcionalista, que privilegia a lógica formal, produtivista, linear - a arte pode ser o instrumento de modificação da percepção da realidade.

Acreditamos que a decisão final de qualquer ação, neste contexto, será regida pela necessidade inerente da empresa de continuar gerando lucro, de forma que qualquer assunto ou iniciativa que estorve este caminho será, na maioria das vezes, contida, freada, domesticada. E é justamente neste ponto que se encontra o perigo deste tipo de associação nas artes e na cultura, e portanto da submissão deste universo aos critérios da iniciativa privada: o que estorva, o que abarca riscos, o que "polemiza" é justo onde possivelmente reside a dimensão transformadora da arte.

\section{Referências}

ARREDONDO, D. G. (2014). Calibán en Cuestión. Aproximaciones teóricas y filosóficas desde nuestra América. Bogotá: Ediciones desde abajo.

BRASIL. Ministério da Cultura (1991). Lei $\mathrm{n}^{\circ}$ 8.313. Restabelece princípios da Lei $n^{\circ}$ 7.505, de 2 de julho de 1986, institui o Programa Nacional de Apoio à Cultura (Pronac) e dá outras providências.

. Ministério da Cultura (2013). Instrução Normativa 01/2013. Estabelece procedimentos para apresentação, recebimento, análise, aprovação, execução, acompanhamento e prestação de contas de propostas culturais, relativos ao mecanismo de incentivos fiscais do Programa Nacional de Apoio à Cultura-Pronac.

CANO, W. (1999). Soberania e Política Econômica na América Latina. São Paulo: editora Unesp.

COELHO, T. (1997). Dicionário Crítico de Política Cultural. São Paulo: Iluminuras.

ECHEVERRÍA, B. (1998). Valor de Uso y Utopía. México: Siglo XXI.

Introducción. In: BENJAMIN, W. La obra de arte en la época de su reproductividad técnica. México: Ítaca, 2003. p. 9-30. (2010). Definición de la Cultura. México: Ítaca / Fondo de Cultura

Económica.

MENDOZA, T. E. Cultura y arte. Una aproximación orientada a la gestión cultural. In: BOLÁN, E. N. (coordenador). Gestión Cultural y Teoría de la Cultura. México: Universidad 
Autónoma Metropolitana y Gedisa, 2015. p. 57-81.

CANCLINI, N. G. (1979). La producción simbólica - teoría y método en sociología del arte. México: Siglo XXI editores, 2014.

HALL, S. (2014a). El trabajo de la representación. In: Eduardo Restrepo, Catherine Walsh, Víctor Vich (coordenadores). Sin Garantías: Trayectorias y problemáticas en estudios culturales. Colombia: Universidad del Cauca editores y Fundación Envión, 2014. p. 489-526.

(2014b). Estudios culturales: dos paradigmas. In: Eduardo Restrepo, Catherine Walsh, Víctor Vich (coordenadores). Sin Garantías: Trayectorias y problemáticas en estudios culturales. Colombia: Universidad del Cauca editores y Fundación Envión, 2014. p. 51-72.

HARVEY, D. (2001) A Produção Capitalista do Espaço. São Paulo: Annablume editora.

MARTEL, F. (2013). Cultura Mainstream. México: Taurus.

OLIVIERI, C. G. (2004). Cultura Neoliberal: leis de incentivo como política pública de cultura. São Paulo: Escrituras Editora.

OSORIO, J. (1999). Fuentes y tendencias de la teoría de la dependencia. In: Marini, R. M. e Millán, M. (coordenadores). La teoría social latinoamericana - Subdesarrollo y dependencia, Tomo II. México: Ediciones El Caballito.

(2014). El estado en el centro de la mundialización - La sociedad civil y el asunto del poder. México: Fondo de Cultura Económica.

PALHANO, A. (2009). A participação dos Grandes. In: Revista Observatório Itaú Cultural n. 07. São Paulo: Itaú Cultural.

QUIJANO, A. (2014). Colonialidad del poder, eurocentrismo y América Latina. In: Antología Esencial - de la dependencia histórico-estructural a la colonialidad / descolonialidad del poder. Ciudad Autónoma de Buenos Aires: CLACSO. 2014. Pp. 777-832.

RUBIM, A. A. C. (2012). Políticas Culturais no Brasil: passado e presente. In: Políticas culturais - coleção Sala de Aula, número 8. Brasil: EDUFBA.

SEGATO, R. L. (2007) La Nación y sus Otros - Raza, etnicidad y diversidad religiosa en tiempos de Políticas de la Diversidad. Buenos Aires: Prometeo libros.

VILLALTA, F. G. Os impactos das políticas públicas no mercado de trabalho na área cultural no início do século XXI no Brasil. 2015. 188 f. Dissertação de mestrado em Desenvolvimento Econômico - Instituto de Economia, Universidade Estadual de Campinas, 2015. Recuperada em http://repositorio.unicamp.br/

WU, Chin-Tao (2006). Privatização da cultura - a intervenção corporativa nas artes desde os anos 80. São Paulo: Boitempo editorial / SESCSP. 